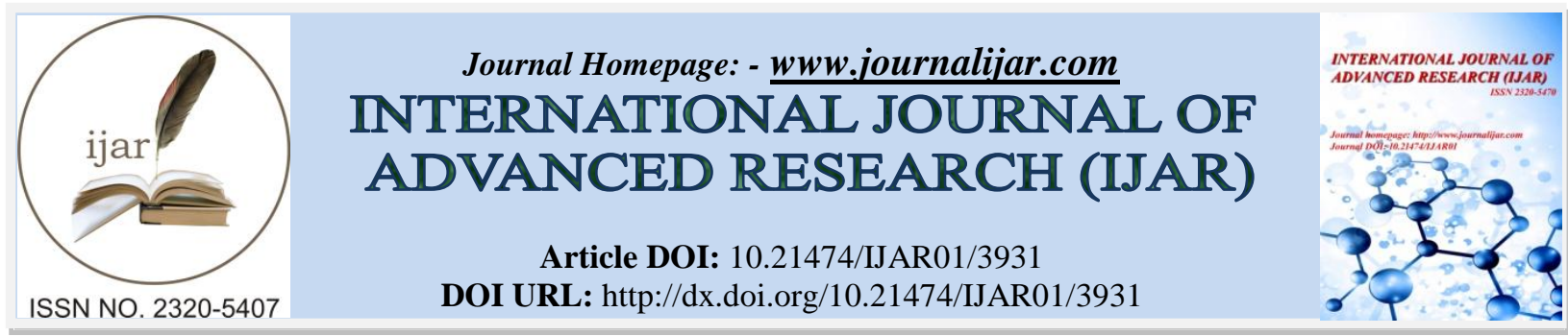

RESEARCH ARTICLE

\title{
A COMPARISON OF NEW SPERM PREPARATION TECHNIQUE BY GLASS WOOL FILTRATION COMBINED WITH PENTOXIFYLLINE WITH OTHER TECHNIQUES IN ASTHENOZOOSPERMIC MEN.
}

Ali A. Kadhim, Hayder A. L. Mossa, Muayad S. Abbood.

High Institute for Infertility Diagnosis and Assisted Reproductive Technologies, Al-Nahrain University, BaghdadIRAQ.

\section{Manuscript Info}

............................

Manuscript History

Received: 18 February 2017

Final Accepted: 19 March 2017

Published: April 2017

\section{Abstract}

Background: Variety of techniques have been developed to separate motile and morphologically normal spermatozoa from other constituents of the ejaculate to optimize successful assisted reproductive technologies.

Objectives: This study is designed to compare the asthenozoospermic semen outcomes of four in vitro sperm activation techniques and evaluate their efficiency, namely; Simple layer technique, Centrifugation technique, Glass wool filtration technique and a new technique of Glass wool filtration combined with Pentoxifylline.

Subjects, Materials and Methods: Forty infertile men with asthenozoospermia were involved in this study. Sperm parameters were assessed according to WHO (2010 and 1999). Post- activation of each sample were divided into four aliquots, the first one :using Simple layer technique, the second :using Centrifugation technique ,the third :Glass wool filtration technique, and last one :using Glass wool filtration technique with Pentoxifylline.

Results: A significant increase of sperm motility, progressive sperm motility and morphologically normal sperm when using Glass wool filtration technique with Pentoxifylline as compared to Glass wool filtration technique. Also, there was a significant increase for the same parameters when using Glass wool filtration technique as compared to the Simple layer and Centrifugation techniques.

Regarding sperm agglutination and Round cells count the study showed the best results by decreasing their levels when using Glass wool filtration combined with Pentoxifylline as compared to other techniques.

Conclusions: From the results of the present study, the sperm function parameters outcome when using glass wool filtration technique combined with Pentoxifylline were superior to other techniques since it yields better sperm function parameters rather than the outcome of glass wool filtration, centrifugation and simple layer techniques; respectively especially when using a low quality of semen samples such as decreased sperm function parameters (sperm motility) so it was fit in cases of asthenozoospermia which taken as an example of infertile group within this study. 


\section{Introduction:-}

Infertility is defined as the inability to become pregnant after 12 months of regular, unprotected intercourse. In a survey from 2006 to 2010, more than 1.5 million U.S. women, or $6 \%$ of the married population 15 to 44 years of age, reported infertility, and 6.7 million women reported impaired ability to get pregnant or carry a baby to term [1]. Among couples 15 to 44 years of age, nearly 7 million have used infertility services at some point [2]. This encompasses couples with infertility and impaired ability to get pregnant, but it does not capture those who are not married, so actual numbers may be underestimated. These numbers are comparable to those of other industrialized nations [3-4]. Infertility may arise from male factors, female factors, or a combination of these factors [5].

Assisted reproductive technologies (ART's) consist of develop into the treatment of option in many cases for male and female infertility. The class of semen samples is one of the factors determining the winning assisted reproduction [6] for that reason, the perfect sperm preparation technique is to reach the largest number of motile spermatozoa, morphologically normal, in a little volume of physiological culture media from seminal plasma, leukocytes, bacteria and debris [7]. With the advancement in the techniques of assisted reproduction, the need to improve sperm processing methods and provision of actively motile spermatozoa has increased tremendously [8]. Glass wool filtration (GWF) technique separate motile spermatozoa from other contents of semen by filtration through densely packed glass wool fibers [9]. Nonviable spermatozoa adhere to the matrix more than motile functional spermatozoa [10]. Immotile and dead spermatozoa may agglomerate because of changes in surface charges [11]. The principle of GWF technique is rested on the self-propelled movement of the spermatozoa and filtration effect of the glass wool fibers [12]. A major advantage of this approach is the selection of normally chromatin- condensed spermatozoa, a parameter considered as predictive for fertilization ability in vitro. The GWF technique is very simple but it is a more expensive procedure[13]. The filtration method is useful for eliminating leukocytes major sources of Reactive Oxygen Species (ROS) and selecting motile and morphologically normal spermatozoa [14].

Pentoxifylline(PX) is a methylxanthine derivative in the same pharmacologic group as caffeine. The PX belongs to a group of vasoactive drugs used in human for treatments of peripheral and cerebral vascular diseases caused by impairment of microcirculation [15]. The PX is also used in treatment of male infertility in human by enhancing sperm motility both in vivo [16] and in vitro [17]. In previous experimental as well as clinical studies, the role of in vitro application of PX on motility of spermatozoa retrieved from different sources of ejaculate, epididymis, and testis were investigated [18]. Pentoxifylline is phosphodiesterase inhibitor that inhibits the breakdown of cyclic adenosine monophosphate (cAMP) [19]. Asthenozoospermia is one of the major causes of infertility or reduced fertility in men [20]. Asthenozoospermia, is defined as 'total motility' (progressive + non-progressive) less than $40 \%$ or progressive motility less than $32 \%$ (WHO, 2010) [21]. Sperm motility is a critical indicator of semen quality and fertility potential because the sperm motility is required for the penetration of cervical mucus, transport through the female genital tract and penetration through the corona radiate and zona pellucida before oocyte fertilization [22].

\section{Subjects, Materials and Methods:-}

Forty infertile men with asthenozoospermia participated in this study during their attendance to the infertility clinics at the High Institute for Infertility Diagnosis and Assisted Reproductive Technologies, Al-Nahrain University . Semen samples were collected and semen analysis was done according to WHO (2010) and (1999). Each semen sample was divided into four aliquots. The first one using the Simple layer technique, the second one using Centrifugation technique, the third using Glass wool filtration(GWF) technique and fourth using Glass wool filtration technique with Pentoxifylline(GWF+PX) (combination technique), then sperm parameters were assessed for these four techniques and the results were statistically analyzed.

\section{Glass wool filtration technique with Pentoxifylline (combination technique):-}

As a new sperm preparation technique was performed as the following, adding $1 \mathrm{~mL}$ of Add $1 \mathrm{~mL}$ of Ferticult Flushing medium + PX to $1 \mathrm{~mL}$ liquefied semen sample then Centrifugation at $2000 \mathrm{rpm}$ for 5 minute and remove supernatant and add 1mL of Ferticult Flushing medium + PX to pellet. Shaking the sample then left for 8-10 minutes in an incubator, after that the semen suspension placed gently over the wet glass wool syringe and allowed 
to filter by gravity. A drop of $10 \mu \mathrm{L}$ was aspirated, put on a slide with cover slip and examined under the microscope at 400X objective to assess the sperm parameters as recommended by WHO (2010) and (1999).

\section{Statistical Analysis:-}

The Statistical Analysis System- SAS (2016) program was used to effect of difference factors in study parameters. Least significant difference -LSD test (ANOVA) or T-Test was used to significant compare between means. Estimate of Correlation coefficient between parameters in this study.

\section{Results:-}

The present study showed a significant decrease in the certain sperm parameters (sperm concentration, sperm agglutination and round cells count) during post-in vitro sperm activation when using these four techniques as compared to pre- activation. While, a significant increase in the other certain sperm parameters (sperm motility, progressive sperm motility and morphologically normal sperm) during post -in vitro sperm activation when using these four activation techniques as compared to pre-activation. Table 1 showed the sperm function parameters for infertile men with asthenozoospermia $(\mathrm{n}=40)$, during pre- and post-in vitro sperm activation techniques. The same table showed a significant decrease for the concentration of sperm when using Glass wool filtration combined with Pentoxifylline technique as compared with pre-activation. In contrast, table (1) showed significant increase in the certain sperm parameters (sperm motility, progressive sperm motility and morphologically normal sperm) when using Glass wool filtration combined with Pentoxifylline as compared with the Glass wool filtration techniques only. Table 1 also showed non- significant difference for the sperm agglutination and round cells count among these three activation techniques.

Table 1:- Sperm Function Parameters for asthenozoospermic infertile men pre- and post- in vitro sperm activation.

\begin{tabular}{|c|c|c|c|c|c|c|c|c|}
\hline \multirow{2}{*}{\multicolumn{2}{|c|}{$\begin{array}{l}\text { Certain sperm function } \\
\text { parameters }\end{array}$}} & \multirow{3}{*}{$\begin{array}{l}\text { Before } \\
\text { activation } \\
44.40 \pm 1.79 \text { a }\end{array}$} & \multicolumn{4}{|c|}{ After in vitro activation } & \multirow{3}{*}{$\begin{array}{l}\text { LSD } \\
\text { value } \\
\begin{array}{l}\text { 6.073 } \\
* *\end{array} \\
\end{array}$} & \multirow{2}{*}{$\begin{array}{c}\mathbf{P}- \\
\text { value }\end{array}$} \\
\hline & & & \multirow{2}{*}{ 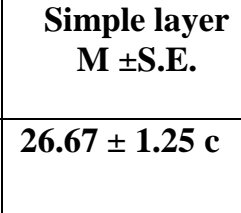 } & \multirow{2}{*}{$\begin{array}{c}\text { Centrifugation } \\
\mathrm{M} \pm \text { S.E. } \\
35.30 \pm 1.72 b\end{array}$} & $\begin{array}{c}\text { Glass wool } \\
\mathrm{M} \pm \text { S.E. }\end{array}$ & $\begin{array}{c}\text { Glass } \\
\text { wool+px } \\
\text { M } \pm \text { S.E. }\end{array}$ & & \\
\hline $\begin{array}{l}\text { Sperm Con } \\
\text { value }(\mathrm{m} / \mathrm{ml})\end{array}$ & ntration & & & & $\begin{array}{l}39.25 \pm 2.11 \\
\text { ab }\end{array}$ & $\begin{array}{l}39.78 \pm 1.74 \\
\text { ab }\end{array}$ & & 0.001 \\
\hline \multirow{3}{*}{$\begin{array}{l}\text { Progressive } \\
\text { Sperm } \\
\text { Motility (\%) }\end{array}$} & $\begin{array}{c}\text { Grade } \\
\text { A }\end{array}$ & $10.78 \pm 0.52 \mathrm{~d}$ & $15.67 \pm 0.75 \mathrm{~cd}$ & $19.00 \pm 0.62 \mathrm{c}$ & $26.87 \pm 0.94 b$ & $35.37 \pm 1.06$ a & $\begin{array}{l}\mathbf{6 . 1 5 8} \\
* *\end{array}$ & 0.001 \\
\hline & $\begin{array}{c}\text { Grade } \\
\text { B }\end{array}$ & $29.95 \pm 0.87 b$ & $40.78 \pm 1.46 a$ & $42.13 \pm 1.33 \mathrm{a}$ & $45.27 \pm 2.28 \mathrm{a}$ & $41.32 \pm 1.74 a$ & $\begin{array}{l}6.733 \\
* * \\
\end{array}$ & 0.001 \\
\hline & $\begin{array}{c}\text { Grade } \\
\text { A+B }\end{array}$ & $40.73 \pm 1.53 \mathrm{c}$ & $56.45 \pm 2.64 b$ & $61.12 \pm 2.97 b$ & $72.27 \pm 3.41 \mathrm{a}$ & $76.70 \pm 3.76 a$ & $\begin{array}{l}7.165 \\
* * \\
\end{array}$ & 0.001 \\
\hline $\begin{array}{l}\text { Non } \\
\text { Progressive } \\
\text { Sperm } \\
\text { Motility (\%) } \\
\end{array}$ & $\underset{\text { Crade }}{\text { Grade }}$ & $38.18 \pm 2.38 \mathrm{a}$ & $29.30 \pm 1.84 b$ & $25.60 \pm 1.05 b$ & $18.50 \pm 0.89 c$ & $16.67 \pm 0.63 \mathrm{c}$ & $\begin{array}{l}\text { 6.738 } \\
* *\end{array}$ & 0.001 \\
\hline $\begin{array}{l}\text { Immotile } \\
\text { Sperm }(\%)\end{array}$ & $\begin{array}{c}\text { Grade } \\
\text { D }\end{array}$ & $21.10 \pm 0.82 a$ & $13.87 \pm 0.63 b$ & $14.73 \pm 0.59 b$ & $9.23 \pm 0.43 \mathrm{c}$ & $6.50 \pm 0.18 \mathrm{c}$ & $\begin{array}{l}\mathbf{4 . 0 6 4} \\
* *\end{array}$ & 0.001 \\
\hline \multicolumn{2}{|c|}{$\begin{array}{l}\text { Morphologically } \\
\text { Normal Sperm (\%) }\end{array}$} & $36.98 \pm 1.57 \mathrm{~d}$ & $41.25 \pm 1.42 \mathrm{~cd}$ & $46.50 \pm 1.77 c$ & $58.62 \pm 2.26 b$ & $66.63 \pm 2.77 a$ & $\begin{array}{l}\mathbf{5 . 9 8 3} \\
* *\end{array}$ & 0.001 \\
\hline \multicolumn{2}{|c|}{$\begin{array}{l}\text { Sperm agglutination } \\
(\%)\end{array}$} & $6.30 \pm 0.17 a$ & $1.75 \pm 0.12 b$ & $0.275 \pm 0.07 \mathrm{c}$ & $0.125 \pm 0.05 c$ & $0.050 \pm 0.03 c$ & $\begin{array}{l}1.419 \\
* * \\
\end{array}$ & 0.001 \\
\hline $\begin{array}{l}\text { Round } \\
\text { (HPF) }\end{array}$ & Count/ & $8.275 \pm 0.16 a$ & $3.15 \pm 0.16 b$ & $\begin{array}{l}1.40 \pm 0.08 \mathrm{~b} \\
\mathrm{c}\end{array}$ & $0.625 \pm 0.07 c$ & $0.625 \pm 0.07 c$ & $\begin{array}{l}2.194 \\
* *\end{array}$ & 0.001 \\
\hline
\end{tabular}

-Means having with the different letters in same column differed significantly

-Data are Mean $(\mathrm{M}) \pm$ Standard Error(S.E.),Number $=40$, ** $(\mathrm{P}<0.01)$ 


\section{Discussion:-}

Sperm preparation techniques are a very important component of assisted reproductive technologies [23] in the meantime, enhancement in the sperm parameters improved the sperm fertilizing capacity and outcomes of ART's [24-25]significantly thought of sperm separation techniques is to the treat spermatozoa in vitro in order to improve their functionality i.e. motility and provide a protective environment with the purpose to maintain or get better their functional capacity for winning fertilization. An advance in the percentages of sperm motility and progressive sperm motility is regarded as normal reply for sperm activity after exclusion of seminal plasma since it contain dead sperm, leukocytes, epithelial cells, debris and microbial contamination that produce many oxygen radicals so as to can negatively influence the sperm functions[26].

In the glass wool filtration technique and glass wool filtration (GWF) combined with Pentoxifylline there are lower decrease in the sperm concentration compared with before activation. These results were in agreement with other studies using culture medium for the separation and activation of sperm in vitro which based on the existence of the higher percentage of good motile sperms in these two methods compared with other methods The current study clarified that significant increase for the progressive sperm motility after when using GWF+PX technique as compared to the GWF techniques. Also, this study clarified that a significant increase for the same parameter postactivation when using the GWF technique as compared to the pre-activation [27-30].

The sperm motility parameters within the techniques of Glass wool filtration alone or with combination with Pentoxifylline showed that the sperm motility Grade A+B were significantly improved in comparison to other techniques, while there were a decrease in the poor sperm motility Grades(C,D). These results were similar to the findings that reported the main improving role of Glass wool filtration which based mainly on the reduction process of dead immotile spermatozoa that are held back by adhesion to glass wool fibers[31].

Sperm morphology is considered as a sensitive indicator of overall testicular health, because the sperm morphological characteristics are determined during spermatogenesis The present study clarified that a significant increase in the normal sperm morphology when using GWF+PX technique as compared to the GWF techniques. Significant increase for the same parameter when using GWF technique as compared to the pre-activation [32]. Also plays a crucial role in the diagnosis of male fertility potential and it has demonstrated a predictive value for fertilization and pregnancy outcomes in IVF [33].

\section{References:-}

1. Chandra A, Copen CE, Stephen EH. Infertility and impaired fecundity in the United States, 1982-2010: data from the National Survey of Family Growth. Natl Health Stat Rep. 2013;(67):1-18.

2. Chandra A, Copen CE, Stephen EH. Infertility service use in the United States: data from the National Survey of Family Growth, 1982-2010. Natl Health Stat Report. 2014;(73):1-21.

3. Bushnik T, Cook JL, Yuzpe AA, Tough S, Collins J. Estimating the prevalence of infertility in Canada [published correction appears in Hum Reprod. 2013;28(4):1151]. Hum Reprod. 2012;27(3):738-746.

4. Oakley L, Doyle P, Maconochie N. Lifetime prevalence of infertility and infertility treatment in the UK: results from a population-based survey of reproduction. Hum Reprod. 2008;23(2):447-450

5. Tammy J. Lindsay, Kirsten R. Vitrikas. Evaluation and Treatment of Infertility. Am Fam Physician. 2015;91(5):308-314.

6. Ezdehar N. Ali, Ula M. R. Al-Kawaz, Muhammad-Baqir M-R. Fakhrildin. A New Sperm Preparation Technique by Combination of Density Gradient Centrifugation and Glass Wool Filtration Techniques Versus Each Oone Alone For Infertile Men With Asthenozoopsemria. Int J Adv Res. 2016; 4( 4):1112-1115.

7. Van Voorhis BJ. Outcomes from assisted reproductive technology. Obstet Gynecol. 2006;107:183-20. Press 2010.pp.167-87

8. Noah L, Jain T, Missmer SA and Hornstein MD. Trends in Assisted Reproductive Technology. N Engl J Med. 2004;35: 398-9.

9. Henkel RR and Schill WB. Sperm preparation for ART. Reprod Biol. Endocrinol. 2003; 1: 108.

10. Bussalleu E, Pinart M, Rivera M, et al. Effects of filtration of semen doses from subfertile boars through neuter Sephadex columns. Reproduction in Domestic Animals. 2008; 43(1):48-52.

11. Ahmad Z, Anzar M, Shahab M, et al. Sephadex and sephadex ion-exchange filtration improves the quality and freezability of low-grade buffalo semen ejaculates. Theriogenology. 2003; 59(5-6): 1189- 1202. 
12. Sanchez R, Concha M, Ichikawa $\mathrm{T}$, et al. Glass wool filtration reduces reactive oxygen species by elimination of leukocytes in oligozoospermic patients with leukocytospermia. J Assist Reprod Genet. 1996;13:489-94.

13. Henkel R, Kierspel E, Stalf T, et al. Effect of reactive oxygen species produced by spermatozoa and leukocytes on sperm functions in non-leukocytospermic patients. Fertil Steril. 2005; 83(3): 635-42.

14. Ibrahim NM, Foster DN and Crabo BG. Localization of clusterin on freeze-preserved bull spermatozoa before and after glass wool-sephadex filtration. Journal of Andrology. 2001; 22(5): 891-902.

15. Muller, R. and Lehrach, F. Huemorheology and nebrovascular disease, multi-functional approach with Pentoxifylline. Curr. Med. Res. and Opin. 1981; 7: 253 - 263

16. Aparirio NJ, Schuarzstein L, and de Turm-ner EA. Pentoxifylline (BL 191) by oral administmtion in the Treatment of intermittent claudication. Angiology. 1980. 35: 407-471.

17. Yovich JM, Edirisinghe WR, Cummins JM, and Yovich JL. Preliminary results using Pentoxifylline pronuclear stage tubal transfer (PROST) program for sever male factor infertility. Fertil. Steril. 1988. 50: 178 - 181.

18. Khalili MA, Vahidi S, Fallah-Zadeh, H. The effect of Pentoxifylline on motility of spermatozoa from asthenozoospermic samples: fresh ejaculates, cryopreserved ejaculates, epididymal, and testicular. Mid. East. Fert. Soc. J. 2001; 6: 144-151.

19. Terriou P, Hans E, Giorgetti C, Spach JL, Salzmann J, Urrutia U. and Roulier R. Pentoxifylline initiates motility in spontaneously immotile epididymal and testicular spermatozoa and allow normal fertilization pregnancy and birth after intracytoplasmic sperm injection. J. Assist. Reprod. Genet. 2000; 17:1949 - 1999 .

20. Aitken RJ, Baker MA and Nixon B. New insights into sperm physiology and pathology. Hand b Exp Pharmacol. 2010;(198):99-115.

21. World Health Organization. WHO laboratory manual for the examination and processing of human semen. 5th edition. Geneva: World Health Organization . 2010.

22. Hadwan MH, Almashhedy LA and Alsalman AS. The key role of zinc in enhancement of total antioxidant levels in spermatozoa of patients with asthenozoospermia. Am J Mol Cell Bio. 2013;1: 52-61.

23. Betancourt M, Resendiz A and Fierro. Effect of two insecticides and two herbicides on the porcine sperm motility patterns using computer assisted semen analysis (CASA) in vitro Reprod. Toxicol. 2006; 22: 508-12.

24. Bavister BD, Kinsey DL, Lane M, et al. Recombinant human albumin supports hamster in vitro fertilization. Hum Reprod 2003; 18: 113- 6.

25. Grasa P, Perez P, Baguena O, et al. Ram sperm selection by a dextran/swimup procedure increase fertilization rates following intrauterine insemination in superovulated Ewes. J. Androl. 2004; 25: 786-790.

26. Bjorndahl L, Mohammadieh M, Pourian M, et al. Contamination by seminal plasma factors during sperm selection. J Androl.2005; 2: 170-73.

27. Check JH, Zavos PM, Katsoff D, and Kiefer D. Effect of Percoll discontinuous density gradients Vs sperm prep II Vs saphedeax G-50 gel filtration on sperm parameters. JEXP. Med. 1993; 169:225-231.

28. Allaw AK. Treatment and in vitro Sperm Activation for Immunologically Infertile Patients.M.Sc. Thesis, College of Medicine. Kufa University. 1999.

29. Tesarik J, Thebauld A, and Testart J. Effect of Pentoxifylline on sperm movement characteristics in normozoospermic and asthenozoospermic specimens. Hum. Reprod. 1992; 7: 1257-1262.

30. Aldujaily S, Khitam M. In vitro Sperm Preparation by Progesterone, Pentoxifylline and Glycyrrhiza Glabra for Asthenozoospermic Men. Global Journal of Medical Research. 2013; 13(1): 1-6.

31. Engel S, Weber H, Petzoldt R, Seidl B, Wiehe W, Sperl J. An improved method of sperm selection by glass wool filtration. Andrologia. 2001; 33, 223-230.

32. Turek PJ. Male infertility. In: Tangho EA and Aninch MC (Eds). Smith general Urology. lange medical Book. New York: McGraw Hill. 2001; 750-787.

33. Antinori M, Licata E, Dani G, et al. Intracytoplasmic morphologically selected sperm injection: a prospective randomized trial.2008; 16, 6: 835-841. 